3) Verschliesse es gut an einem trocknen Orte.

4) Lasse das Mehl nicht zn alt werden, weil es an Gewicht verliert. Das schwarze Mehl, welches viel Kleien enthält, ist schwer aufzuheben. Das Mittelmehl wird mit der Zeit bitter. Auch die Kleien lassen sich schwer aufheben, erhitzen sich leicht und fangen sogar an zu brennen. Grobe Kleien lassen sich besser aufheben als feine, Roggenkleien besser als Weizenkleien. (Karl Hennig, der wohlunterrichtete Bärkermeister, Meissen 1843. S. 12-14.). -

\title{
Nachtrag im Betreff der Samen des Wachtelweizens.
} (Melampyrum arvense L.).

Die noch nicht ganz reifen Samen dieses lästigen Unkrantes geben, frisch zerrieben mit 90 procentigem Weingeist ansgekocht, einen gelblich gefärbten, beim Erkalten sich weisslich trübenden Anszug, der, mit verdünnter Salzsiiure gekocht, sich rasch dunkel fürbt (schmutzig bräunlich violett); die Färbung bleibt auch nach Zusatz von vielem Wasser noch sehr deutlich.

Es enthalten sonach jene Samen ein ähnliches Chromogen, wie die Samen von Alectorolophus (Rhinanthus) hirsutus. Ich werde versuchen, dasselbe $z u$ isoliren.

Jena, den 16. Juli 1871.

H. $L$. 